\title{
Atividade bactericida precoce: uma metodologia segura
} e necessária

A tuberculose representa mundialmente um grande desafio em saúde pública. No Brasil, a taxa de incidência annual é de 51,3/100.000 pessoas (MINISTÉRIO DA SAÚDE, 2002). De acordo com STYBLO (MINISTÉRIO DA SAÚDE, 2002), a incidência da tuberculose será reduzida se forem diagnosticados pelo menos 70\% dos pacientes positivos a baciloscopia de escarro e curados pelo menos 85\% desses pacientes; caso contrário a endemia não será controlada.

No Brasil, os pacientes são tratados com quimioterapia de curta duração durante seis meses, que inclui rifampicina, isoniazida e pirazinamida durante os primeiros dois meses, seguidos de rifampicina e isoniazida durante os próximos quatro meses. 0 uso dessas duas drogas durante os últimos quatro meses é justificado com base na atividade das mesmas sobre os bacilos de crescimento lento intracelulares bem como sobre aqueles de crescimento intermitente presentes na necrose caseosa, o que é essencial para a esterilização bem sucedida das lesões teciduais (MINISTÉRIO DA SAÚDE, 2002).

A quimioterapia de curta duração é altamente eficaz uma vez que ela pode atingir 95\% de cura (MINISTÉRIO DA SAÚDE, 2002). No entanto, seis meses representam um período demasiadamente longo para garantir taxas elevadas de aderência. Portanto, a identificação de novas drogas que permitam encurtar o tempo de tratamento representa uma das prioridades para os programas de controle de tuberculose em todo o mundo.

0 objetivo primário dos ensaios clínicos para a avaliação de novas drogas ou esquemas terapêuticos para tratamento de tuberculose é a cura sem recidiva dois anos após o término do tratamento. A taxa de cura de 95\% alcançada com a quimioterapia de curta duração representa um desafio para os ensaios clínicos devido ao tamanho considerável da amostra necessária para demonstrar significância estatística entre os grupos controle (associação de três drogas) e teste (com a nova droga adicionada). 0 elevado número de pacientes a ser incluído e a necessidade de acompanhar os pacientes durante no mínimo dois anos são responsáveis pela longa duração e pelo elevado custo financeiro desses ensaios, duas características não atrativas para a indústria farmacêutica. Metodologias mais rápidas e com menor custo vem sendo desenvolvidas para avaliação rápida de novas drogas. A atividade bactericida precoce (ABP) representa uma dessas metodologias (MITCHISON, 1993).

A atividade bactericida precoce consiste em quantificar a carga bacilar (número de unidades formadoras de colônias [UFCs] em meio de cultura sólido) presente nos espécimens de escarro coletados durante 12 horas $(19 \mathrm{~h}-7 \mathrm{~h})$ durante os primeiros dois dias de tratamento. Tal metodologia é baseada no fato de que a redução do número de UFC durante os primeiros dois dias está estatisticamente relacionada com a eficácia dos esquemas terapêuticos empregados e representa um parâmetro clínico de redução da infecciosidade (JINDANI e cols., 1980; KENNEDY e cols., 1993). Os estudos de ABP podem ser usados para comparar a atividade de várias doses de uma droga, diferentes drogas dentro da mesma classe e diferentes classes de drogas. Portanto, esses estudos representam uma etapa preliminar útil para obtenção rápida de informações sobre atividade de uma droga em humanos com tuberculose (JINDAN1 e cols., 1980; MITCHISON, 1998).

A atividade tecidual esterilizante de uma droga anti-tuberculosa é calculada medindo a taxa de redução da carga bacilar. Esse tipo de análise é denominado estudo prolongado da ABP. Essa metodologia é baseada num estudo recente de $\mathrm{ABP}$ de isoniazida administrada via oral em doses diárias de $300 \mathrm{mg}$ e 18,5 mg, rifampicina $600 \mathrm{mg}$ e ofloxacina $800 \mathrm{mg}$ durante cinco dias. A ABP da isoniazida praticamente desapareceu após dois dias de uso da droga. Em contraste, a atividade bactericida da rifampicina se manteve por no mínimo cinco dias (SIRGEL e cols., 2000). 
Pacientes não tratados previamente com baciloscopias de escarro positiva são tratados com uma droga, geralmente durante sete dias. Diariamente durante 12 a 16 horas, é coletado o volume de escarro que o paciente conseguir expectorar. Essas amostras de escarro são submetidas a culturas quantitativas. Pacientes com hemoptise e formas graves de tuberculose tais como doença miliar ou meningoencefalite que exijam intervenção terapêutica urgente não são elegíveis. Uma vez atingido os sete dias de uso oral da droga, os pacientes devem completar a quimioterapia padrão de curta duração. 0 teste de sensibilidade as drogas é geralmente realizado anterior ao tratamento e ao final do estudo.

Torna-se uma prioridade sensibilizar a comunidade científica internacional para a necessidade de estudos de ABP das drogas antimicrobianas como uma metodologia rápida de pesquisa para escolher a droga mais promissora a ser adicionada a um esquema antimicobacteriano (GILLESPIE e cols., 2002).

Durante os últimos anos, foram estudadas durante duas semanas as ABPs das drogas antituberculosas administradas isoladamente ou em associação. Esse procedimento permite a quantificação precisa do número de unidades formadoras de colônias por militro de escarro e a quantificação da atividade antimicrobiana de cada droga no pulmão durante esse intervalo.

Os estudos de ABP podem, teoricamente, aumentar o risco de resistência adquirida as drogas estudadas através da seleção de bacilos naturalmente resistentes presentes na carga microbiana (MINISTÉRIO DA SAÚDE, 2002). Os estudos realizados antes da era da poliquimioterapia conduziram ao surgimento de resistência após 20 dias de uso da streptomicina como monoterapia em 109 pacientes com tuberculose pulmonar tratados em ensaios clínicos subsidiados pelo BRITISH MEDICAL RESEARCH COUNCIL (1948). Em relação a monoterapia com isoniazida, TOMAN (1980) descreveu o surgimento de resistência a essa droga somente após uso da mesma durante seis semanas.

Se for considerado os vários estudos de $A B P$ publicados durante os últimos 22 anos, não existe nenhum caso descrito de resistência adquirida após uso da droga por um período de dois dias a duas semanas (JINDANI e cols., 1980; DIETZE e cols.,
2001; DONALD e cols., 2001; DONALD e cols., 2001; DONALD e cols., 2001; DONALD e cols., 2002). Esse intervalo não foi suficiente para selecionar bacilos naturalmente resistentes a droga levando-se em consideração a lenta replicação do M. tuberculosis (18-24 horas). Portanto, como GILLESPIE e cols. (2002) ressaltaram, o estudo de $\mathrm{ABP}$ de uma droga antimicobacteriana representa um estudo eticamente justificado uma vez que não há risco de indução de resistência durante o curto período de uso da droga. Atualmente, moxifloxacina, gatifloxacina, levofloxacina e linezolida (oxazolidinona) representam as drogas mais promissoras com atividade contra $M$. tuberculosis (GOSLING et al., 2003).

Em suma, é absolutamente indispensável a realização de estudos para comparar a ABP dessas drogas com a da isoniazida em pacientes com tuberculose pulmonar positivos a baciloscopia de escarro. Tais estudos permitirão a comunidade científica internacional escolher em curto espaço de tempo a melhor associação antimicobacteriana a ser na

alisada em ensaios clínicos de encurtamento de tratamento.

Moises Palaci, David Jamil Hadad, Valdério do Valle Dettoni, Reynaldo Dietze

Núcleo de Doenças Infecciosas/Centro Biomédico/ Universidade Federal do Espírito Santo

\section{REFERÊNCIAS}

1. Brasil. Ministério da Saúde. Fundação Nacional de Saúde. Centro de Referência Prof. Hélio Fraga. Sociedade Brasileira de Pneumologia e Tisiologia. Controle da tuberculose: uma proposta de integração ensino-serviço. $5^{\circ}$ ed. 2002.

2. British Medical Research Council. Streptomycin treatment of pulmonary tuberculosis. A Medical Research investigation. Brit Med J 1948; 2:769-783.

3. Dietze R, Teixeira L, Rocha LM, Palaci M, Johnson JL, Wells C, Rose L, Eisenach K, Ellner JJ. Safety and bactericidal activity of rifalazil in patients with pulmonary tuberculosis. Antimicrob Agents Chemother 2001; 45:1972-1976.

4. Donald PR, Sirgel FA, Venter A, Smit E, Parkin DP, Van de Wal BW, Mitchison DA. The early bactericidal activity of a low-clearance liposomal amikacin in pulmonary tuberculosis. J Antimicrob Chemother 2001; 48:877-880.

5. Donald PR, Sirgel FA, Venter A, Parkin DP, Van de Wal BW, Barendse A, Smit E, Carman D, Talent J, Maritz J. Early bactericidal activity of amoxicillin in combination with clavulanic acid in patients with sputum smearpositive pulmonary tuberculosis. Scand J Infect Dis 2001; 33:466-469. 
6.Donald PR, Sirgel FA, Venter A, Smit E, Parkin DP, Van de Wal BW, Mitchison DA. The early bactericidal activity of amikacin in pulmonary tuberculosis. Int J Tuberc Lung Dis 2001; 5:533-538.

7.Donald PR, Sirgel FA, Venter A, Smit E, Parkin DP, Van de Wal BW, Dore CJ, Mitchison DA. The early bactericidal activity of streptomycin. Int J Tuberc Lung Dis 2002; 6:696-698.

8.Gillespie SH, Gosling RD, Charalambous BM. A reiterative method for calculating the early bactericidal activity of antituberculosis drugs. Am J Respir Crit Care Med 2002; 166:31-35.

9.Gosling RD, Uiso LO, Sam NE, Bongard E, Kanduma EG, Nyindo M, Morris RW, Gillespie SH. The bactericida activity of moxifloxacin in patients with pulmonary tuberculosis. Am J Respir Crit Care Med, 2003; 168:13421345.

10. Jindani A, Aber VR, Edwards EA, Mitchison DA. The early bactericidal activity of drugs in patients with pulmonary tuberculosis. Am Rev Respir Dis 1980; 121:939-949.
11.Kennedy N, Fox R, Kisyombe M, Saruni OS, Uiso LO, Ramsey AR, Ngowi Fl, Gillespie SH. Early bactericidal and sterilizing activities of ciprofloxacin in pulmonary tuberculosis. Am Rev Respir Dis 1993; 48:1547-1551.

12. Mitchison DA. Assessment of new sterilizing drugs for treating pulmonary tuberculosis by culture at 2 months. Am Rev Respir Dis 1993; 147:1062-1063.

13. Mitchison DA. Basic concepts in chemotherapy of tuberculosis. Em: Gangadharam PRJ; Jenkins PA eds. Mycobacteria 11 Chemotherapy. New York: Chapman Hall 1998; 15-50.

14. Sirgel FA, Donald PR, Odhiambo J, Githui W, Umapathy KC, Paramasivan CN, Tam CM, Lam KM, Lam CW, Sole KM, Mitchison DA, EBA Collaborative Study Group. A multicentre study of the early bactericidal activity of antituberculosis drugs. J Antimicrob Chemother 2000; 45:859-870.

15. Toman K. Organización Panamericana de la Salud. Tuberculosis - Deteccion de casos y quimioterapia. Publicacion Científica 1980; 392. 